\title{
Percepção de ambiente e condiçóes de trabalho de músicos de orquestra
}

\author{
Clarissa Stefani Teixeira ${ }^{a}$, Fausto Kothe ${ }^{\mathrm{b}}$, Luis Felipe Dias Lopes ${ }^{\mathrm{c}}$, Érico Felden Pereira ${ }^{\mathrm{d}}$ \\ aSociedade Educacional de Santa Catarina - SOCIESC, Florianópolis, SC, Brasil

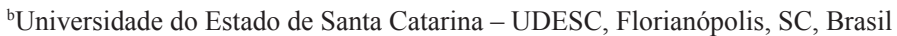 \\ 'Departamento de Administração, \\ Universidade Federal de Santa Maria - UFSM, Santa Maria, RS, Brasil \\ ${ }^{\mathrm{d}}$ Centro de Ciências da Saúde e do Esporte, \\ Universidade do Estado de Santa Catarina - UDESC, Florianópolis, SC, Brasil
}

\begin{abstract}
Resumo: O objetivo deste estudo foi investigar a percepção de ambiente e condições de trabalho de 11 músicos de cordas (viola e violino), de ambos os sexos, em uma orquestra. Foi aplicado um questionário com informações sociodemográficas e a escala Perfil do Ambiente e Condições de Trabalho de Nahas et al. (2009), que considera os componentes ambiente físico, ambiente social, desenvolvimento e realização profissional, remuneração e benefícios e relevância social do trabalho. O ambiente social foi o componente que apresentou maiores escores, $8,00(1,50)$ pontos, seguido da realização profissional, $7,11(1,96)$ pontos, e do ambiente físico, $6,89(0,93)$ pontos. O componente que mostrou menor pontuação, $6,78(1,56)$ pontos, foi associado à remuneração e aos benefícios proporcionados pela orquestra. De maneira geral, os músicos apresentaram percepções positivas dos componentes relacionados ao perfil do ambiente e condições do trabalho. No entanto, a remuneração e a relevância social das atividades são pilares do trabalho e o investimento nelas poderia colaborar para a melhoria das condições de trabalho desses profissionais.
\end{abstract}

Palavras-chave: Condições de Trabalho, Ambiente de Trabalho, Saúde Ocupacional, Música.

\section{Perception of orchestral musicians about work environment and conditions}

\begin{abstract}
The objective of this study was to investigate the perception of 11 orchestral string (viola and violin) musicians of both genders with respect to their work environment and conditions. We applied a questionnaire with demographic information and the scale Profile of Work Environment and Working Conditions by Nahas et al. (2009), which analyzes the following components: physical environment, social environment, development and professional achievement, salary and benefits, and social relevance. The social environment component presented the highest score - 8.00 (1.50 points), followed by professional achievement - 7.11 (1.96 points), and physical environment - 6.89 ( 0.93 points). The salary and benefits provided by the orchestra presented the lowest score - 6.78 (1.56 points). In general, the musicians showed positive perceptions of the components related to work environment and working conditions. However, remuneration and social relevance are work bases that could contribute to improve the working conditions of these professionals.
\end{abstract}

Keywords: Working Conditions, Working Environment, Occupational Health, Music. 


\section{Introdução}

A ergonomia visa analisar, propor e promover mudanças no ambiente e nas condições de trabalho, aperfeiçoando e adaptando espaços, rotinas, máquinas e equipamentos utilizados na execução das tarefas, de acordo com as características físicas e condições psicológicas do trabalhador. Além de segurança, saúde e conforto, as intervençôes ergonômicas têm por objetivo promover maior eficiência e eficácia no trabalho executado (SILVA; SOUZA; MINETTI, 2002).

Especificamente relacionado ao trabalho dos músicos, pesquisas evidenciam que se trata de uma atividade que proporciona altos riscos de adoecimento ocupacionais (PHILIPSON et al., 1990; BERQUE; GRAY, 2002; COSTA; ABRAHÃO, 2004; FJELLMAN-WIKLUND et al., 2004; ARAÚJO; CARDIA, 2005; TEIXEIRA; LOPES; MERINO, 2009; TEIXEIRA et al., 2010), principalmente, quando se trata das atividades dos instrumentistas de violino e viola. Essas propensóes estáo associadas às peculiaridades estruturais dos instrumentos, que não são apoiados no chão e exigem assimetrias dos membros superiores para a execução (COSTA; ABRAHÃO, 2004; FJELLMAN-WIKLUND et al., 2004; ARAÚJO; CARDIA, 2005; COSTA, 2005).

Além da intensa exigência física de trabalho, as cargas psicológica e organizacional podem interferir de forma importante no desenvolvimento das atividades desses profissionais. Segundo Jourdain (1997), Gates (2001) e Costa (2003), a rigidez hierárquica presente em orquestras é comparável à da carreira militar no que tange à estratificação e às restriçốes disciplinares. Além disso, em outras profissóes pode-se dizer que o trabalho associa-se à produção e ao consumo de bens materiais, permeando-se de componentes como obrigatoriedade, responsabilidade, organização, o controle do tempo e do espaço (ISAYAMA; MOURA, 2008), enquanto na música, além de essas situações também serem observadas, deve também a prática instrumental ser contemplada com procedimentos de organização e operacionalização de forma equilibrada (WILLIAMON, 2004).

Segundo Silva et al. (2007), estratégias de organização do trabalho influenciam a percepçáo dos níveis de esforço e de dor no seu desenvolvimento. Nesse mesmo contexto de análise, Nahas et al. (2009) indicam que há evidências de que o ambiente e as condiçóes de trabalho (além do estilo de vida) têm grande influência na saúde e na qualidade de vida de todos os indivíduos. Assim, no contexto de vida atual, fatores socioambientais (o ambiente e as condiçôes de trabalho, no caso do trabalhador) somados a fatores individuais (estilo de vida) formam a percepção de bem-estar geral do indivíduo, o que se reflete na sua qualidade de vida.

Porém estudos que busquem identificar a percepção dos músicos relacionando as questōes do ambiente de trabalho são ainda escassos, constituindo uma lacuna de conhecimento no desenvolvimento de estratégicas ergonômicas para esses trabalhadores. Essas questôes sáo exploradas por Fragelli e Günther (2009) quando discutem que muitos estudos deixam de ser desenvolvidos na área da música pela falsa ideia de que música associa-se apenas a lazer, estando, portanto, raramente relacionada a atividades laborais. Baseando-se nessas premissas, o presente estudo buscou identificar a percepção que têm os músicos de suas condiçóes e ambiente de trabalho no contexto de atividades de uma orquestra.

\section{Materiais e métodos}

Este estudo caracteriza-se, segundo Thomas e Nelson (2002), como estudo descritivo-exploratório, de corte transversal, no qual foi realizado um levantamento de informações ainda pouco investigadas em uma determinada população. Utilizou-se procedimentos quantitativos (aplicação de questionários) e qualitativos (observaçôes do ambiente de trabalho e entrevistas abertas com os músicos). O presente estudo foi aprovado pelo Comitê de Ética em Pesquisas com Seres Humanos da instituição de origem e atendeu às determinaçóes da legislação vigente.

O estudo foi conduzido junto a uma orquestra semiprofissional da Região Sul do Brasil composta por 29 músicos. Para efeito de análise foram investigados os 11 instrumentistas de viola e violino (nove homens). Optou-se por focar as análises nos músicos de viola e violino por tratar-se de musicistas especialmente expostos a problemas ergonômicos e à carga física (ZAZA; CHARLES; MUSZYNSKI, 1998).

Para avaliação da percepção sobre as condições de trabalho foi utilizado o instrumento proposto por Nahas et al. (2009) denominado Perfil de Ambiente e Condições de Trabalho, formado por 15 questôes dentro de uma escala de quatro níveis ( 1 = ruim, 2 = regular/sofrível, 3 = bom/boa e 4 = excelente). $\mathrm{O}$ instrumento busca avaliar o ambiente e as condiçốes de trabalho considerando cinco componentes: (1) ambiente físico, (2) ambiente social, (3) desenvolvimento e realização profissional, (4) remuneração e benefícios, (5) relevância social do trabalho. 
Os componentes citados são formados por questôes específicas da seguinte forma: (1) ambiente físico (condiçôes de limpeza e iluminação do local de trabalho; adequação ergonômica de mobiliário e equipamentos; condições de ruído e temperatura); (2) ambiente social (relacionamento com os demais trabalhadores; relacionamento com seu(s) chefe(s) imediatos(s); oportunidade para expressar opinióes relacionadas ao trabalho); (3) desenvolvimento e realizaçáo profissional (crescimento e aperfeiçoamento profissional oferecidos pela instituição; nível de conhecimento/habilidade para realizar suas tarefas; grau de motivação e ânimo ao chegar para trabalhar); (4) remuneraçáo e benefícios (remuneração em relação ao trabalho que realiza; benefícios de saúde oferecidos pela instituição aos trabalhadores; oportunidades de lazer e congraçamento entre trabalhadores e familiares); e (5) relevância social do trabalho (imagem da instituição perante a sociedade; relevância do seu trabalho para a instituição e a sociedade; nível de equilíbrio entre sua vida profissional e pessoal/ familiar).

O instrumento, avaliado por Botti et al. (2006) através do Kappa, na avaliação da reprodutibilidade obteve o valor 0,6353 (IC 95\%: 0,6041; 0,6665), apresentando $77,6 \%$ de concordância nas respostas entre o teste e o reteste e recebendo classificaçáo, portanto, de substancial. Além disso, Nahas et al. (2009), ao realizarem a reprodutibilidade dessa mesma escala encontraram níveis de concordância substanciais, portanto aceitáveis para reprodutibilidade (coeficiente de Kappa de 0,63 (IC 95\%: 0,60; 0,66), apresentando 77,6\% de concordância das respostas entre o teste e o reteste).

A percepçáo dos músicos foi interpretada como percepçáo negativa ou percepção positiva para cada componente do questionário. Os componentes do questionário possuem pontuação possível de zero a nove, sendo que pontuaçóes maiores indicam percepção mais positiva do ambiente de trabalho. Considerando o valor máximo (nove), foi adotada metade da pontuação como ponto de corte. Assim, foram considerados como percepção negativa valores médios da escala de 0 a 4,49 pontos e percepçáo positiva valores de 4,50 a 9 pontos. Os dados foram analisados por meio de estatística descritiva (média e desvio padrão).

Os pesquisadores, com objetivo de compreender as atividades e rotinas de trabalho dos músicos de orquestra, realizaram observaçóes in loco e questionamentos acerca das atividades dos instrumentistas. As observaçôes foram realizadas durante os ensaios coletivos do grupo e de naipe, totalizando aproximadamente 25 horas. Além disso, foram realizadas em torno de oito horas de observação das apresentações, incluindo-se a preparação anterior aos espetáculos.

\section{Resultados e discussão}

A idade média dos músicos foi de 24,27 (10,09) anos e a média de prática do instrumento de 6,09 $(6,95)$ anos. Na orquestra, os músicos tocavam em média há 2,91 $(2,39)$ anos. Atividades individuais e coletivas caracterizam a jornada de trabalho dos instrumentistas. As atividades individuais são desenvolvidas fora do ambiente da orquestra e há possibilidade de escolha individual quanto a local e tempo de prática.

Os instrumentos que constituem a orquestra avaliada são: naipe das cordas: violino, viola, violoncelo e contrabaixo; naipe das madeiras: flauta transversa e clarinete; naipe dos metais: trompete e trombone (ilustrados na Figura 1).

Para realizar a tarefa prescrita, indicada por Guérin et al. (2001) e Iida (2005), que no caso dos músicos é a execução da obra musical, o trabalho deve ser desenvolvido de tal forma que haja esforços individuais e coletivos, visto que todos os instrumentistas atuam buscando o mesmo objetivo, ou seja, construir a interpretação da obra. Para que isso ocorra, a integração de todos os naipes de instrumentos, os quais se articulam frente às determinaçóes da obra musical e da interpretaçáo dada pelo maestro, é fundamental. Mesmo com a especialização instrumental, todos os esforços individuais convergem para a construção sonora da obra musical, o que caracteriza uma atividade coletiva de trabalho de integraçáo e harmonia entre as partes.

O posto de trabalho dos músicos, no geral, é constituído de interações entre os colegas, maestro, instrumento, partituras e a prática em si (estudos e apresentaçóes). De maneira geral, o posto de trabalho permite, além das interações entre instrumento e músico, interaçôes feitas com os demais músicos. Os grupos de instrumentos ficam dispostos em fileiras, formando um semicírculo de frente para o maestro (Figura 2). A tarefa prescrita no trabalho dos músicos pode ser determinada da seguinte forma: desenvolver estudos individuais, de naipe (com seus respectivos orientadores - chefes de naipe), e coletivos (com participação de todos os músicos previstos pela obra musical) objetivando a interpretação da obra a ser executada, bem como participar dos ensaios; dividir o posto de trabalho com o colega durante a 


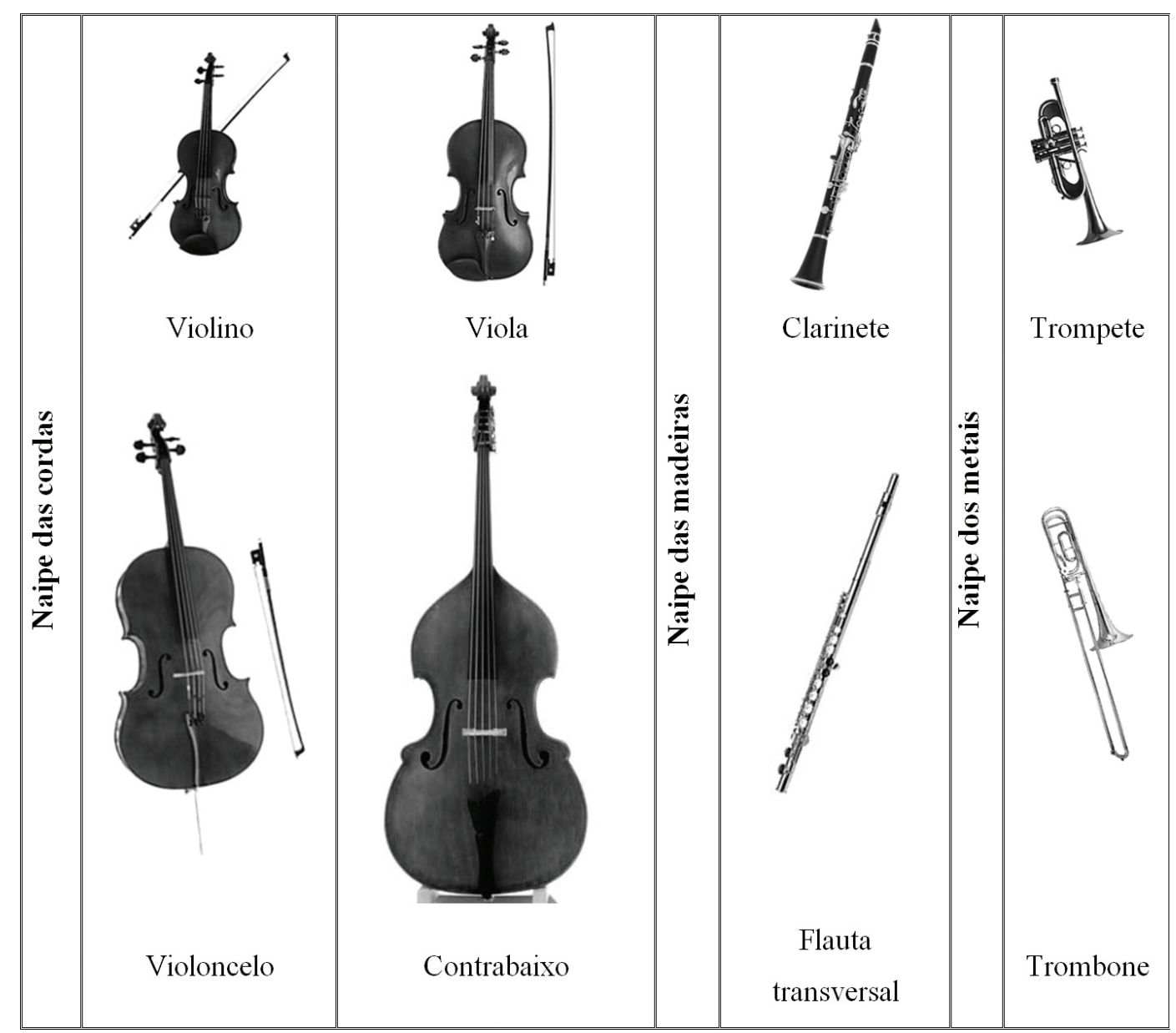

Figura 1. Instrumentos musicais que constituem a orquestra avaliada. Fonte: Teixeira et al. (2009).

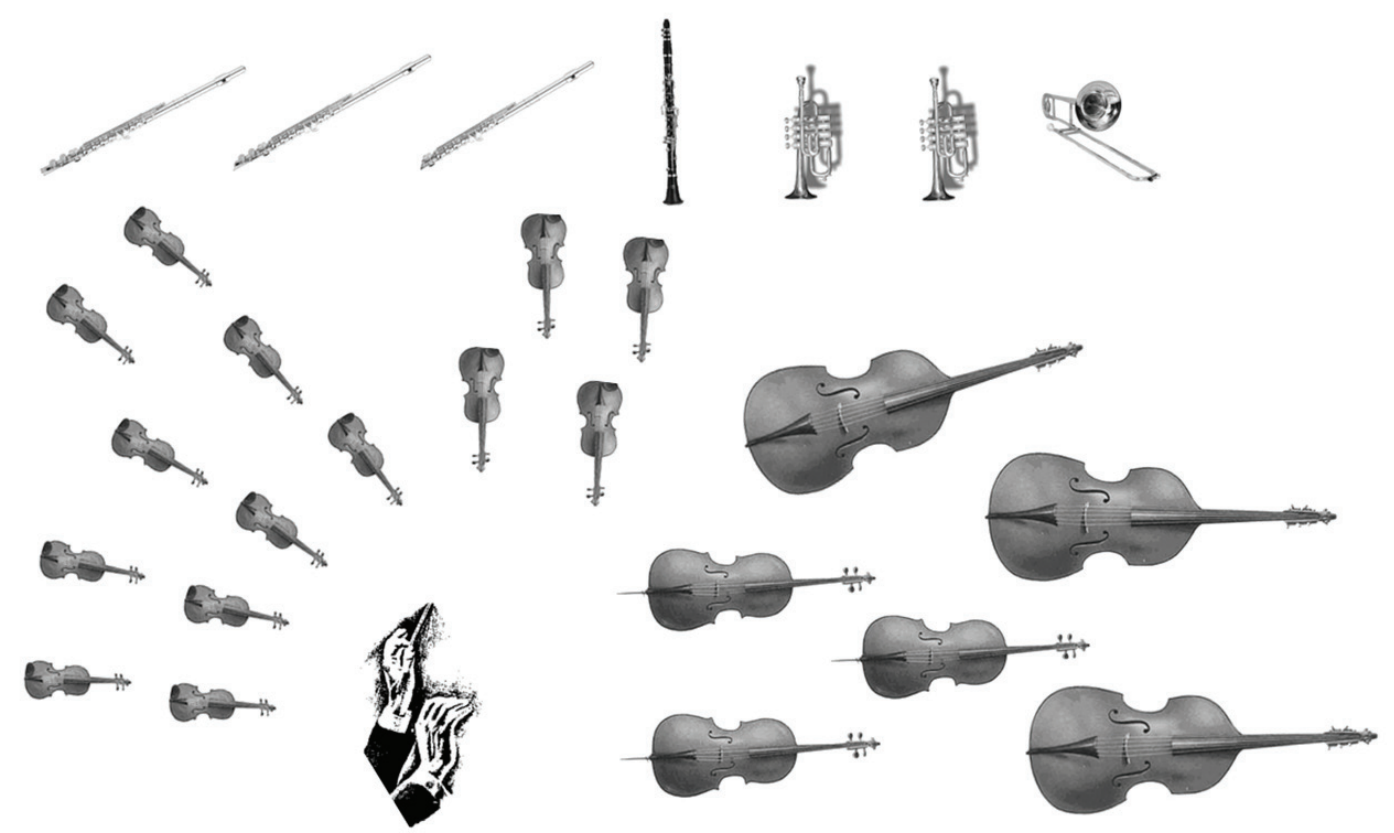

Figura 2. Posicionamento dos postos de trabalho da orquestra durante as atividades coletivas. 
prática com a orquestra; posicionar-se como indica a Figura 2, de forma que haja visualização dos gestos do maestro e possa haver a leitura das partituras musicais, uma vez que precisam seguir fielmente as orientaçóes gráficas prescritas; interpretar e seguir as orientaçôes do maestro, spalla (primeiro músico na fila dos violinos) e chefe de naipe (primeiro músico na fila de cada tipo de instrumento) na construçáo da obra, verificando as informaçóes repassadas durante o transcorrer da prática; ler a partitura atentando para notas e pausas etc. e tocar o instrumento interagindo com seu próprio naipe e com todos os outros naipes de instrumentos da orquestra; participar das apresentaçôes; seguir normas como pontualidade, vestuário e viagens; levar o instrumento musical para o trabalho.

O trabalho dos instrumentistas avaliados normalmente se dá em quatro momentos distintos, sendo eles: a) estudos individuais com o instrumento; b) estudos com o naipe do instrumento; c) ensaios com a orquestra; e d) apresentaçóes. A apresentação se dá em dois momentos: 1) apresentação com toda a orquestra e 2) apresentaçáo individual ou em grupos nos chamados saraus. As apresentaçôes seguem um cronograma anual e são normalmente realizadas nos finais de semana, em locais diversificados, como clubes, igrejas, ao ar livre etc., na cidade de origem da orquestra e na região.

Os instrumentistas avaliados pelo presente estudo realizavam suas atividades individuais durante 2,27 $(2,15)$ horas por dia, $5,27(1,27)$ dias por semana. Os estudos coletivos (de naipe e ensaios com a orquestra) totalizam 3,64 $(0,92)$ horas, sendo realizados como descritos na tarefa prescrita, aos sábados, na própria instituição. Com relação ao tempo de trabalho na orquestra, esse foi de $2,91(2,39)$ anos.

A Tabela 1 ilustra os resultados relacionados aos componentes do questionário no que se refere a ambiente físico, social, desenvolvimento e realização profissional, remuneração e benefícios e relevância social do trabalho.

A Figura 3 ilustra uma representação pictorial do ambiente e das condiçôes de trabalho dos instrumentistas avaliados, obtida por meio dos valores da moda das respostas dos instrumentistas em cada questão do questionário.

De acordo com os resultados encontrados, o ambiente social foi aquele que obteve maior pontuação, ou seja, foi o componente do ambiente de trabalho com percepção mais positiva pelos músicos investigados. Assim, o relacionamento com os demais trabalhadores e com os chefes e a oportunidade de expressar suas opiniôes relacionadas ao trabalho são questôes que contribuem para a satisfação desse grupo de trabalhadores.

Os resultados do presente estudo associados à percepção positiva do ambiente social vão de encontro às indicações de Jourdain (1997), Gates (2001) e Costa (2003), que referem rigidez no sistema das orquestras, o que indica uma visão mais contemporânea de modelos organizacionais (GABRIEL; LUCAS; DE CAMARGO, 2009).

Além disso, essas diferenças podem estar relacionadas ao fato de os autores associarem orquestras profissionais nas quais a demanda de trabalho é alta, principalmente no que se refere a carga horária e apresentaçóes. A orquestra avaliada pode ser considerada semiprofissional, pois associa-se a projetos de uma instituição de ensino à qual vincula-se.

É a instituição que fomenta o trabalho dos membros da orquestra e, como essa é de ensino superior, há integração com a Pró-Reitoria de Extensão e Relaçōes Comunitárias, através do departamento artístico-cultural, que se relaciona diretamente com as atividades realizadas. A orquestra é constituída por um maestro que, além de reger as obras escolhidas por ele e muitas vezes arranjadas, deve fazer a integraçáo dos músicos para que a obra seja executada. De forma geral, é de responsabilidade do maestro a orientação técnica e artística dos instrumentistas da orquestra, bem como a participação na elaboração da programação e do cronograma de trabalho necessários ao desenvolvimento das atividades propostas pelo departamento artístico.

Tabela 1. Média e desvio padrão dos componentes do perfil do ambiente e condições do trabalho conforme a percepção dos instrumentistas.

\begin{tabular}{lcc}
\hline \multicolumn{1}{c}{ Componentes } & Média & Desvio padrão \\
\hline Ambiente físico & 6,89 & 0,93 \\
Ambiente social & 8,00 & 1,50 \\
Desenvolvimento e realização profissional & 7,11 & 1,96 \\
Remuneração e benefícios & 5,56 & 2,07 \\
Relevância social do trabalho & 6,78 & 1,56 \\
\hline
\end{tabular}




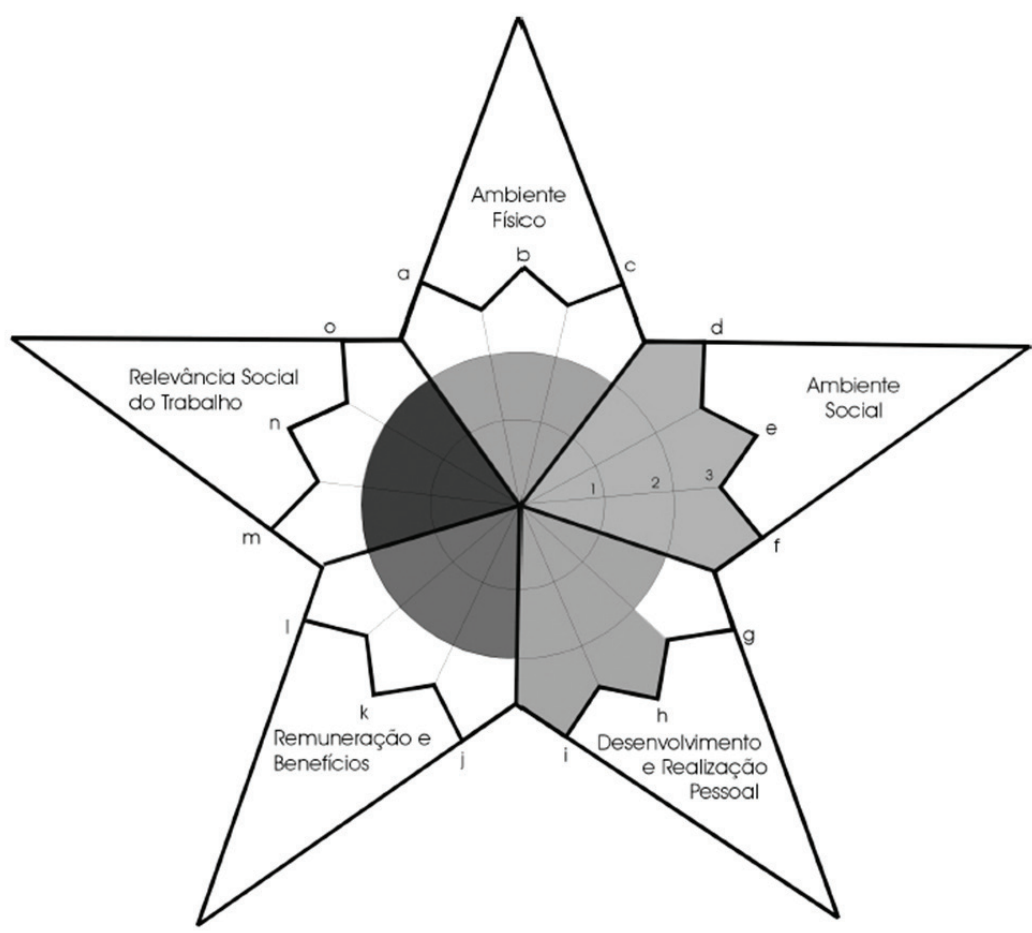

Figura 3. Representação pictorial do ambiente e das condições de trabalho dos instrumentistas de corda (violino e viola).

Deve-se salientar que a orquestra avaliada não possui uma equipe de apoio, como outras orquestras, por exemplo, arquivistas, armadores, secretária e equipe artística (PETRUS, 2005), o que pode acabar sobrecarregando os integrantes da orquestra e, no caso, o maestro, considerado o mais ativo do quadro. Porém, o estudo de Petrus (2005) também demonstrou atividades concentradas no maestro, responsável pela coordenação e orientação técnica e artística dos músicos da orquestra e que também participa na elaboração da programação e do cronograma de trabalho necessários ao desenvolvimento das atividades propostas pela diretoria artística, além de reger a orquestra.

A Figura 4 ilustra a estrutura organizacional da orquestra avaliada. O spalla (primeiro violinista) é o representante musical do maestro diante da orquestra. Tem a função de solista no seu instrumento e é de sua responsabilidade conduzir a afinação da orquestra e determinar tecnicamente as arcadas (posição dos arcos) para os instrumentos de corda. Aos chefes de naipe dos instrumentos cabe coordenar as atividades conjuntamente com o maestro e o spalla, posicionar os músicos do seu naipe, coordenar a disciplina e conduzir os ensaios de naipe, de forma a ensinar as obras (leitura da partitura, arcadas, tempos etc.) a serem executadas durante o ensaio. Os demais músicos da orquestra devem seguir as orientaçóes

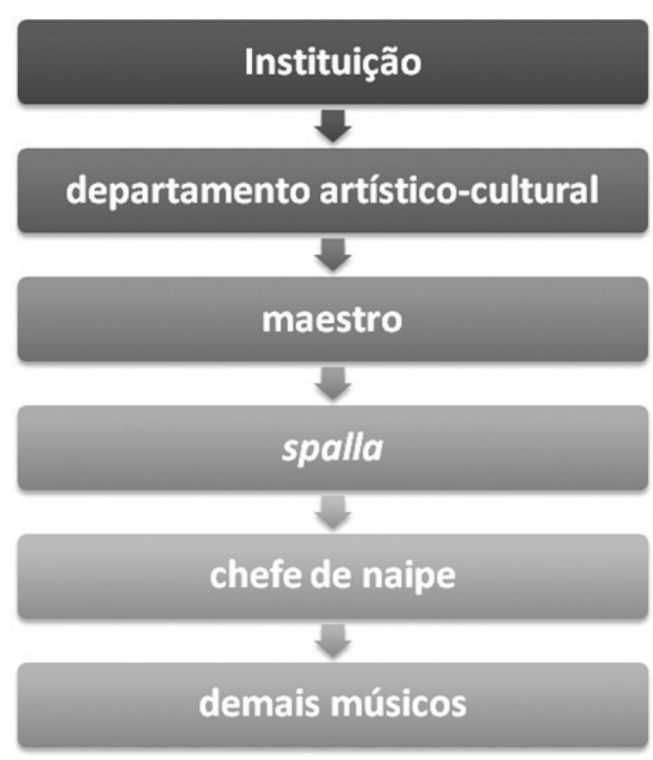

Figura 4. Estrutura organizacional da orquestra.

determinadas pelo maestro, pelo spalla e pelo chefe do naipe de seu grupamento instrumental.

Da mesma forma que no estudo de Gabriel, Lucas e De Camargo (2009), as decisóes acabam sendo tomadas pelas pessoas mais autossuficientes e comprometidas com as atividades propostas. Nesse caso, visualizam-se as funçôes do spalla e 
chefes de naipe como efetivas durante os ensaios de naipe e com toda a orquestra. Porém, de fato, as ligaçôes entre instituição e instrumentistas e demais representantes clientes que contratam a orquestra são prioritariamente desenvolvidas pelo maestro e esse acaba por conduzir a maior parte das atividades e fazer a mediação entre os diferentes integrantes da orquestra.

Segundo a percepção dos instrumentistas, a interação entre os membros da orquestra foi considerada como o principal ponto positivo $[8,00$ $(1,50)$ pontos], o que converge para um ambiente social agradável e que auxilia na prática profissional. Petrus (2005) informa que dentro do contexto da produção orquestral o trabalho coletivo envolve um conjunto de relaçóes sociais. Segundo a mesma autora, as interaçôes entre os músicos ocorrem durante os ensaios e apresentaçóes, o que exige o compartilhamento de um ambiente comum de trabalho e a construção de resultados coletivos mediante a comunicação e a cooperação.

Para Mendes e Abrahão (1996), na medida em que as relaçóes com os pares e a hierarquia são fragilizadas pela organização do trabalho, há maior dificuldade para estabelecer um coletivo de trabalho, levando ao sofrimento. Por outro lado, a valorização e o reconhecimento de competências por colegas e hierarquia são fontes de vivências prazerosas que aliam-se aos investimentos sublimatórios propiciados pela atividade, o que, consequentemente, reflete-se na motivação para o desenvolvimento das atividades. Além disso, em ambientes de trabalho, as indicaçóes são para o trabalho coletivo, de forma a se agregar maior conhecimento e sensibilidade, permitindo melhores decisôes (CHIAVENATO, 2005; ROBBINS, 2006; ARAUJO, 2007).

Ao se abordar a dimensão coletiva do trabalho deve-se considerar as interrelaçóes e a intersubjetividade (relaçóes entre as pessoas) e não apenas a relação sujeito-tarefa (DEJOURS, 1997). Nesse sentido, Leitão, Fortunato e Freitas (2006) indicam que a questão dos relacionamentos interpessoais é crucial para a vida associada, pois são esses processos interativos que formam o conjunto de sistemas que a organizam. Para os autores, as condiçôes em que ocorrem tais relacionamentos definem a forma de convivência entre os seres humanos, que são seres de relaçóes, e deles com a natureza.

O trabalho em equipe e o desenvolvimento de relações profissionais positivas incentivam o desenvolvimento do sentimento de vinculação e de cooperação dentro dos grupos de trabalho (MORIM, 2001). No que se refere ao trabalho, o relacionamento entre os trabalhadores pode fazer a diferença entre o sofrimento e o bem-estar que, segundo Leitão, Fortunato e Freitas (2006), define como a vida social é construída ou deteriorada no cotidiano, por meio das relaçóes sociais, inter e intraorganizacionais.

O trato dos relacionamentos interpessoais, como forma de dominação sobre o trabalho, gera resultados limitados e perversos, tanto ao bem-estar no trabalho quanto à produtividade. De forma geral, para haver aumento espontâneo da produtividade do trabalho é preciso elevar o nível de qualidade nos relacionamentos entre todos os que operam a empresa (LEITĀO; FORTUNATO; FREITAS, 2006). Além disso, Dejours (1985) aponta como um dos principais pontos de conflito e, por consequência, provocadores de sofrimento psíquico, as relaçóes, muitas vezes rígidas, entre o trabalhador e a organização. Essa relação pode ser considerada conflituosa por ter, de um lado, a expectativa do trabalhador e, do outro, a rigidez sobre o modo de funcionamento e produçáo da organização, impedindo o trabalhador de atribuir um sentido particular ao seu trabalho.

Segundo Morim (2001), o prazer e o sentimento de realização que podem ser obtidos na execução de tarefas dão sentido ao trabalho. Essas consideraçôes associam-se aos escores atribuídos ao componente realização profissional $[7,11(1,96)$ pontos].

A realização profissional, segundo Nahas et al. (2009), está associada às oportunidades e aperfeiçoamento profissional, nível de conhecimento, habilidade para realizar as tarefas e grau de motivação ao chegar para trabalhar. Morim (2001) destaca que o sentido que uma pessoa encontra na função exercida, o sentimento de responsabilidade que ela vivencia em relação aos resultados obtidos e o conhecimento de seu desempenho no trabalho apresentam impacto importante na motivação e na satisfação da pessoa em seu trabalho.

Além disso, se os trabalhadores sentem-se preocupados apenas com o cumprimento das regras e normas determinadas pela empresa, como forma de conseguir uma boa avaliação da organização, os objetivos centrais da atividade são desviados (ANGELONI, 2003). Nesse sentido, pode-se dizer que os instrumentistas avaliados têm a possibilidade de focar suas atividades na performance instrumental. Além disso, a possibilidade de realizar estudos diários em locais diversificados (determinados pelos próprios músicos) parece ser um ponto importante para o andamento das atividades sem pressáo da organização. 
Nesse sentido, Coury (1999) afirma que a pressão imposta aos trabalhadores na produçáo pode contribuir para o aumento do número de casos de doença. Da mesma forma, Vahtera, Kivimäki e Pentti (1997) encontraram relação entre pressão sobre os trabalhadores e aumento do risco de lesóes musculoesqueléticas e acidentes de trabalho, devido à repetitividade e ao clima de insegurança presentes no local de trabalho, o que, consequentemente, favorece os afastamentos por motivos de saúde. Assim, Silva et al. (2007) indicam que as mudanças nos processos produtivos promovidas pelas empresas para adequarem-se às exigências da economia globalizada e cada vez mais competitiva podem trazer consequências sérias para a saúde do trabalhador.

O fato de haver percepção positiva para o componente social e para a realização do trabalho pode influenciar a percepçáo em quesitos como o ambiente físico. Esse componente associa as condições de limpeza, iluminação, ruído e temperatura do local de trabalho e adequaçóes ergonômicas e de equipamentos.

No caso do trabalho com os instrumentistas, os dados da literatura apontam principalmente para prejuízos advindos do ambiente físico, associados à perda auditiva induzida pelo ruído (PAIR) (McBRIDE et al., 1992; MARCHIORI; MELO, 2001; MENDES; KOEMLER; ASSENCIO-FERREIRA, 2002; MILLER; STEWART; LEHMAN, 2007; AMORIM et al., 2008; MARTINS et al., 2008), e das adequaçóes ergonômicas e de equipamentos como, por exemplo, a queixeira e a espaleira (BRANDFONBRENER, 1989; LEVY et al., 1992; STEINMETZ; SEIDEL; NIEMIER, 2008).

Segundo a Classificação Internacional de Ergonomia, disponível em http://www. acaoergonomica.ergonomia.ufrj.br/edicoes/vol2n1/ artigos/1.pdf, a carga física associa-se à anatomia humana, antropometria, fisiologia e biomecânica em relação à atividade física, sendo tópicos relevantes para as análises de postura no trabalho, manuseio de materiais, movimentos repetitivos, distúrbios musculoesqueléticos relacionados ao trabalho, projetos de postos de trabalho, segurança e saúde. Assim, as queixas musculoesqueléticas podem ser citadas como predominantes na profissão (ANDRADE; FONSECA, 2000; GLATZ; POFFO; PRZSIEZNY, 2006; TEIXEIRA; LOPES; MERINO, 2009; TEIXEIRA et al., 2010).

No que se associa às queixas musculoesqueléticas (como dor, desconforto e até mesmo lesões), há associação das inadequaçóes com o instrumento (ANDRADE; FONSECA, 2001) e com os postos de trabalho, que no caso dos instrumentistas, além do instrumento musical, necessitam de estante, partitura musical e cadeira, pois na orquestra as atividades são desenvolvidas com o trabalhador predominantemente sentado. Assim como em outros estudos, foi observado que no local de trabalho, nas atividades coletivas, estante e partitura são elementos divididos por dois músicos e que as cadeiras não possuem regulagens. Essas questôes necessitam ser investigadas de forma mais aprofundada para a compreensão da real interferência dessas nas condiçôes de trabalho, assim como para evitar interferências negativas do ambiente físico e na qualidade de vida dos trabalhadores (SILVA; SOUZA; MINETTI, 2002).

A relevância social do trabalho caracteriza-se, segundo Nahas et al. (2009), pela imagem e relevância da empresa perante a sociedade e pelo nível de equilíbrio entre a vida profissional e pessoal/familiar do trabalhador. Esse componente também apresentou percepçóes positivas [6,78 $(1,56)$ pontos]. Assim, parece que o desafio proposto pela instituiçáo é encarado como significativo no que se refere à valorização da cultura musical, visto a prática desenvolvida pela orquestra. Cabe ressaltar que, na cidade, essa é a única atividade que movimenta a cultura relacionada à música erudita que também apresenta obras populares.

Por se tratar de um projeto que envolve prática caracterizada como semiprofissional, o quesito de menor pontuação associa-se à remuneraçáo, sendo ela uma das fragilidades da orquestra. Nesse sentido, Tamayo e Paschoal (2003) relacionam que a valorização dos empregados está associada à satisfação dos trabalhadores. Para Carvalho e Silva (2006), em uma era de competitividade, a remuneração fixa tornou-se insuficiente para motivar e incentivar as pessoas a desenvolverem comportamento proativo, empreendedor e eficaz na busca de metas e resultados excelentes. Para os autores, diferentemente dos resultados encontrados, a remuneração não apresenta associação com a motivação, pois funciona apenas como fator higiênico.

Porém, Erez (1997) salienta que essas questôes podem influenciar na dimensão da motivação e, consequentemente, a desmotivaçáo dos trabalhadores pode interferir na disposição para dedicar esforço, conhecimentos e habilidades pessoais ao trabalho. Assim, valorização dos trabalhadores é de fundamental importância se a organização pretender manter um lugar de destaque no mercado altamente competitivo de hoje. Na profissão musical, Fragelli e Günther (2009) avaliaram 46 instrumentistas e encontraram relatos de que a profissão ainda é pouco valorizada. Além disso, segundo resultados dos 
mesmos autores, a remuneração é incompatível com as exigências das atividades do trabalho. Essas questóes acabam prejudicando as atividades profissionais e aumentando a carga psíquica. Destaca-se, no entanto, que a remuneração dos profissionais investigados e a relevância social de sua atividade são pilares do trabalho e que o investimento nelas poderia colaborar para a melhoria das condiçóes de trabalho.

\section{Conclusão}

$\mathrm{O}$ ambiente social parece ser o principal fator a contribuir para a percepção positiva do ambiente de trabalho no grupo investigado. Já os componentes do ambiente de trabalho cuja percepção é mais negativa estão relacionados com a remuneração e os benefícios proporcionados pela orquestra e com a relevância social do trabalho. Tais dimensôes constituem questóes importantes para açōes ergonômicas e de políticas públicas voltadas para a melhoria das condiçóes de trabalho desses profissionais.

\section{Agradecimentos}

Os autores agradecem a Diego Spagnuelo, da Universidade Federal de Santa Catarina, pela vetorização das imagens.

\section{Referências}

AMORIM, R. B. et al. Alteraçôes auditivas da exposição ocupacional em músicos. Arquivos Internacionais de Otorrinolaringologia, São Paulo, v. 12, n. 3, p. 377-383, 2008

ANDRADE, E. Q.; FONSECA, J. G. M. Artista-atleta: reflexôes sobre a utilização do corpo na performance dos instrumentos de cordas. Performance Musical, Belo Horizonte, v. 2, p. 118-128, 2000.

ANDRADE, E. Q.; FONSECA, J. G. M. O músico e seu corpo. Fisio\&Terapia, Rio de Janeiro, v. 25, p. 22, 2001.

ANGELONI, M. T. Organizaçōes do conhecimento - infraestrutura, pessoas e tecnologias. São Paulo: Saraiva, 2003.

ARAUjO, L. C. Organização sistema e métodos. São Paulo: Atlas, 2007.

ARAÚJO, N. C. K.; CARDIA, M. C. G. A presença de vícios posturais durante a execução do violino. In: CONGRESSO BRASILEIRO DE BIOMECÂNICA, 10., 2005, João Pessoa. Anais... João Pessoa: Sociedade Brasileira de Biomecânica, 2005. CD-ROM.

BERQUE, P.; GRAY, H. The Influence of neck-shoulder pain on trapezius muscle activity among professional violin and viola players: an electromyographic study. Medical Problems of Performing Artists, Rochester, v. 17, n. 2, p. 68-75, 2002.

BOTTI, M. et al. Perfil do ambiente e condiçóes de trabalho: consistência dos resultados em trabalhadores de diferentes graus de escolaridade. Revista Brasileira de Ciência e Movimento, Brasília, v. 14, n. 4, p. 103, 2006.

BRANDFONBRENER, A. G. Interview with Cho-Liang (Jimmy) Lin. Medical Problems of Performing Artists, v. 4, n. 1, p. 3-8, 1989.

CARVAlHO, A. C.; SILVA, B. V. M. A motivação para o trabalho com enfoque no aspecto financeiro. In: SIMPÓSIO DE ENGENHARIA DA PRODUÇÃO, 13., Bauru, 2006. Anais... Bauru: Universidade Estadual Paulista, 2006.

CHIAVENATO, I. Administração nos novos tempos. Rio de Janeiro: Editora Campus, 2005.

COSTA, C. P. Quando tocar dói: Análise ergonômica da atividade de violistas de orquestra. 2003. $136 \mathrm{f}$. Dissertação (Mestrado em Psicologia)-Universidade de Brasília, Brasília, 2003.

COSTA, C. P. Contribuiçóes da ergonomia à saúde do músico: consideraçóes sobre a dimensão física do fazer musical. Música Hodie, Goiânia, v. 5, n. 2, p. 53-63, 2005. COSTA, C. P.; ABRAHÃO, J. I. Quando o tocar dói: um olhar ergonômico sobre o fazer musical. Performance Musical, Belo Horizonte, v. 10, p. 60-79, 2004.

COURY, H. J. C. G. The effects of production changes on the musculoskeletal disorders in Brazil and South America. International Journal of Industrial Ergonomics, Clemson, v. 25, n. 103-104, p. 1999.

DEJOURS, C. O fator humano. Rio de Janeiro: Editora Fundação Getúlio Vargas, 1997.

DEJOURS, C. Organisation du Travail - clivage - alienation. In: DEJOURS, C.; VEIL, C.; WISNER, A. Psychopatologie du travail. Paris: EME, 1985. p. $123-130$.

EREZ, M. A culture-based model of work motivation. In: EARLY, C.; EREZ, M. (Eds.). New perspectives on international industrial/organizational psychology. San Francisco: The New Lexington Press, 1997. p. 193-242.

FJELLMAN-WIKLUND, A. et al. Trapezius muscle activity pattern in string players: Part I-is there variability in the playing technique? International Journal of Industrial Ergonomics, Clemson, v. 33, p. 347-356, 2004.

FRAGELLI, T. B. O.; GÜNTHER, I. A. Relação entre dor e antecedentes de adoecimento físico ocupacional: um estudo entre músicos instrumentistas. Performance Musical, Belo Horizonte, v. 19, p. 18-23, 2009.

GABRIEL, L. C.; LUCAS, I. A.; DE CAMARGO, G. R. Organizações Saudáveis: Uma análise da estrutura e modelos contemporâneos de gestão em uma empresa multinacional do interior paulista. Inovação, Gestão e Produção, Santa Maria, v. 1, n. 7, p. 9-14, 2009.

GATES, D. The Philharmonic's new admiral takes command. Newsweek, Amsterdam, v. 138, n. 2, p. 56-57, 2001.

GLATZ, C. V. D. H.; POFFO, P.; PRZSIEZNY, W. L. Análise da incidência de dor e desconforto em músicos de Blumenau-SC. Fisio\&Terapia, Rio de Janeiro, n. 51, p. 18-19, 2006.

GUÉRIN, F. et al. Compreender o trabalho para transformá-lo: a prática da ergonomia. São Paulo: Edgard Blücher; Fundaçâo Vanzolini, 2001. 
IIDA, Í. Ergonomia projeto e produção. São Paulo: Edgar Blucher, 2005.

ISAYAMA, H. F.; MOURA, R. C. B. Lazer e trabalho: olhar de profissionais de educação física que atuam no âmbito do lazer. Arquivos em Movimento, Rio de Janeiro, v. 4, n. 2, p. 64-77, 2008.

JOURDAIN, R. Música, cérebro e êxtase. Rio de Janeiro: Objetiva, 1997. PMCid:PMC508345

LEITÁO, S. P.; FORTUNATO, G.; FREITAS, A. S. Relacionamentos interpessoais e emoções nas organizações: uma visão biológica. Revista de Administração Pública, Rio de Janeiro, v. 40, n. 5, p. 883-907, 2006.

LEVY, C. E. et al. Electromyographic analysis of muscular activity in the upper extremity generated by supporting a violin with and without a shoulder rest. Medical Problems of Performing Artists, v. 7, n. 4, p. 103-109, 1992.

MARCHIORI, L. L. M.; MELO, J. J. Comparação das queixas auditivas com relação à exposição ao ruído em componentes de orquestra sinfônica. Pró-Fono, São Paulo, v. 13, n. 1, p. 9-12, 2001.

MARTINS, J. P. F. et al. Avaliação da perda auditiva induzida por ruído em músicos de Tubarão-SC. Arquivos Catarinenses de Medicina, Florianópolis, v. 37, n. 4, p. 69-74, 2008.

McBRIDE, D. et al. Noise and the classical musician. British Medical Journal, London, v. 305, p. 19-26, 1992. http://dx.doi.org/10.1136/bmj.305.6868.1561

MENDES, A. M.; ABRAHÃO, J. I. Organização do trabalho e vivências de prazer-sofrimento do trabalhador: abordagem psicodinâmica. Psicologia: Teoria e Pesquisa, Brasília, v. 12, p. 179-184, 1996.

MENDES, M. H.; KOEMLER, L. A.; ASSENCIOFERREIRA, V. J. A prevalência de perda auditiva induzida pelo ruído em músicos de banda instrumental. Revista CEFAC, São Paulo, v. 4, n. 3, p. 179-185, 2002.

MILLER, V. L.; STEWART, M.; LEHMAN, M. Noise exposure levels for student musicians. Medical Problems of Performing Artists, Rochester, v. 22, n. 4, p. 160-165, 2007. MORIM, E. M. Os sentidos do Trabalho. Revista de Administração de Empresas, v. 41, n. 3, p. 8-19, 2001.

NAHAS, M. V. et al. Reprodutibilidade de uma escala para avaliar a percepçáo dos trabalhadores quanto ao ambiente e às condiçôes de trabalho. Revista Brasileira de Saúde Ocupacional, São Paulo, v. 34, n. 120, p. 179-183, 2009. http://dx.doi.org/10.1590/S0303-76572009000200009

PETRUS, A. M. F. Produção musical e desgaste musculoesquelético: elementos condicionantes da carga de trabalho dos violinistas de uma orquestra. 2005. 116 f. Dissertação (Mestrado em Engenharia de
Produção)-Universidade Federal de Minas Gerais, Belo Horizonte, 2005.

PHILIPSON, L. et al. Muscular load levels in performing musicians as monitored by quantitative electromyography. Medical Problems of Performing Artists, Rochester, v. 5, n. 2, p. 79-82, 1990.

ROBBINS, S. Comportamento Organizacional. São Paulo: Pearson Prentice Hall, 2006.

SILVA, F. P. S. et al. Níveis de percepção de esforço e de dor em duas estratégias de organização do trabalho. Fisioterapia em Movimento, Curitiba, v. 20, n. 1, p. 53-60, 2007.

SILVA, K. R.; SOUZA, A. P.; MINETTI, L. J. Avaliação do perfil de trabalhadores e das condições de trabalho em marcenarias no município de Viçosa-MG. Revista Árvore, Viçosa, v. 26, n. 6, p. 769-775, 2002.

STEINMETZ, A.; SEIDEL, W.; NIEMIER, K. Shoulder pain and holding position of the violin. Medical Problems of Performing Artists, v. 2, n. 23, p, 79-81, 2008.

TAMAYO, A.; PASCHOAL, T. A relação da motivação para o trabalho com as metas do trabalhador. Revista de Administração Contemporânea, v. 7, n. 4, p. 33-54, 2003.

TEIXEIRA, C. S. et al. Superuso musculoesquelético e fatores associados em músicos de orquestra. Motriz, Rio Claro, v. 16, n. 1, p. 17-27, 2010.

TEIXEIRA, C. S. et al. Trabalho e prática de exercícios físicos: o caso de músicos de orquestra. Lecturas, Educación Física y Deportes, Buenos Aires, v. 13, n. 130, p. 1-, 2009.

TEIXEIRA, C. S.; LOPES, L. F. D.; MERINO, E. A. D. $A$ atividade do músico de orquestra: prática instrumental e desconforto corporal. Boletim Brasileiro de Educação Física, Brasília, v. 9, n. 74, p. 10-16, 2009.

THOMAS, J. R.; NELSON, J. K. Métodos de pesquisa em atividade física. Porto Alegre: ArtMed, 2002.

VAHTERA, J.; KIVIMÄKI, M.; PENTTI, J. Effect of organizational downsizing on health of employees. Lancet, London, v. 350, p. 1124-1128, 1997. http://dx.doi. org/10.1016/S0140-6736(97)03216-9

WILLIAMON, A. Musical excellence: strategies and techniques to enhance performance. Oxford: University Press, 2004. PMid:15561499. http://dx.doi.org/10.1093/ acprof:oso/9780198525356.001.0001

ZAZA, C.; CHARLES, C.; MUSZYNSKI, A. The meaning of playing-related musculoskeletal disorders to classical musicians. Social Science \& Medicine, Oxford, v. 47, n. 12, p. 2013-2023, 1998. http://dx.doi.org/10.1016/ S0277-9536(98)00307-4

\section{Contribuição dos Autores}

Clarissa Stefani Teixeira e Fausto Kothes participaram da elaboração do projeto, escolha dos instrumentos, coleta e análise dos dados e redação do artigo. Luis Felipe Dias Lopes e Érico Felden Pereira participaram da elaboração do projeto, escolha dos instrumentos, análise dos dados e redação do artigo. 